\title{
Design of a Microstrip Patch Antenna with High Bandwidth and High Gain for UWB and Different Wireless Applications
}

\author{
Zain Ul Abedin and Zahid Ullah \\ Department of Electrical Engineering, CECOS University of IT \& Emerging Sciences, Peshawar, Pakistan
}

\begin{abstract}
We propose square shape patch antenna in this research work. Focus of the work is to obtain large bandwidth with compact ground plane for wireless applications. The proposed antenna is designed using dielectric material of FR4 having height of $1.6 \mathrm{~mm}$ and having $\epsilon_{r}$ of 4.4. We simulated the proposed antenna in CST Microwave Studio. Simulation results show that the proposed antenna achieved bandwidth from $2.33 \mathrm{GHz}$ to 12.4 GHz with radiation efficiency more than $90 \%$ in ultrawideband range. The proposed antenna covers the range of ultra wideband from $3.1 \mathrm{GHz}$ to $10.6 \mathrm{GHz}$, the range of local area network, wide area network, and also covers the range of satellite communications (for both uplink and downlink).
\end{abstract}

Keywords-High bandwidth, patch antenna, low profile, linear polarization

\section{INTRODUCTION}

Antenna is one of the basic building blocks of wireless applications. Antenna plays an important role in telecommunication industry and is used to transmit and collect electromagnetic (EM) waves. Antenna is a metallic device acts as transducers, which transfers and also receives EM waves. Antennas are present everywhere; at homes, automobiles, roads, houses, police stations, radar system, parks, satellite communications buildings, and military devices. Television antennas in early days are manufactured to receive the air broadcast signals; those signals are transmitted having frequency at about 41 $\mathrm{MHz}$ to $250 \mathrm{MHz}$ in very high frequency and also $470 \mathrm{MHz}$ to $960 \mathrm{MHz}$ in ultra-high frequency ranges among different countries.

In the end of $20^{t h}$ century, scientists were able to do many inventions like computers, mobile phones, laptops, local area network, bluetooth, routers, jammers, military missile applications, aircraft, satellites communication, and rockets. For the reason of those inventions, scientists need such an antenna which is light in weight, cheap in cost, having good performance, portable, and easy to fabricate. Microstrip patch antenna can be printed on circuit boards. Microstrip patch antennas are mostly used in mobiles phones and laptops, etc. Patch antennas are cheap in cost, having low profile, and easy to fabricate. Patch antennas have three parts-patch, substrate, and ground. Substrate is composed of dielectric materials such as Arlon, FR4, foam, polystyrene, and roger. Ground and patch are made from metals.

The patch antennas are a famous type of the antennas from the frequency range of $1 \mathrm{GHz}$ to $11 \mathrm{GHz}$. Deschamps suggested the idea of microstrip patch antennas in 1953. On the other hand, in early 1970, Howell and Munson were able to design a practical antenna. The antennas they designed have dual dimensional arrangements and are normally identified as patch antennas. The common arrangement of patch antenna can be made up of a radiator on front side of the substrate while a ground plane on the back side of patch antenna. There are various shapes of patch antennas for example square, rectangular, circular, triangular, dipole, and elliptical. A lot of advantages of those antennas such as lesser volume, easy to integrate, and also have the ability to handle both linear and circular polarization, and to permit double and triple frequency operations. Feed lines and matching circuits can be fabricated jointly with the antennas design.

Patch antennas have some limitations as well such as its bandwidth is very small and gain is also not good. Thus, different techniques are developed to increase its bandwidths and gain. In this letter, the proposed antenna is square in shape, which operates in the range of $2.33 \mathrm{GHz}$ to $12.4 \mathrm{GHz}$; thus, accomplishing the UWB bandwidth improvement. UWB range is from $3.1 \mathrm{GHz}$ to $10.6 \mathrm{GHz}$, which is officially certified by federal communication commission at America in 2002.

The proposed antenna covers the ultra wideband range, also achieves the range of worldwide interoperability for microwave access (WIMAX-1(2.300-2.400GHz), WIMAX2(2.496 to 2.690), WIMAX-3(3.300 to 3.800), and WIMAX-4 (5.25-5.85 GHZ)), local area network band (wifi-1(2.412 to 2.4835), wifi-2(4.9 to 5.9)) works in personal area network (Bluetooth(2.402 to 2.480)), also works in satellite communications bands for both downlink (3.7 to $4.2 \mathrm{GHz}$ ) and uplink (5.925 to $6.425 \mathrm{GHz}$ ).

Rest of the paper is organized as follows: Section II discusses problem statement, literature review, and outlines contributions of the work, Section III explains basic structure of the proposed antenna design, while Section IV shows its simulation results from CST Microwave Studio.

\section{BACKGROUND AND CONTRIBUTIONS}

\section{A. Problem Statement}

The main limitation of microstrip patch antenna is the lower bandwidth, which effects wireless communication applications. Bandwidth of microstrip antenna can be improved by increasing the height of substrate by using the transmission line model. At the same time, increasing height of the substrate also increases the surface waves, which move from end to end around the substrate and spread at the curves of the radiating patch, which adopts apart of energy of the signal; 


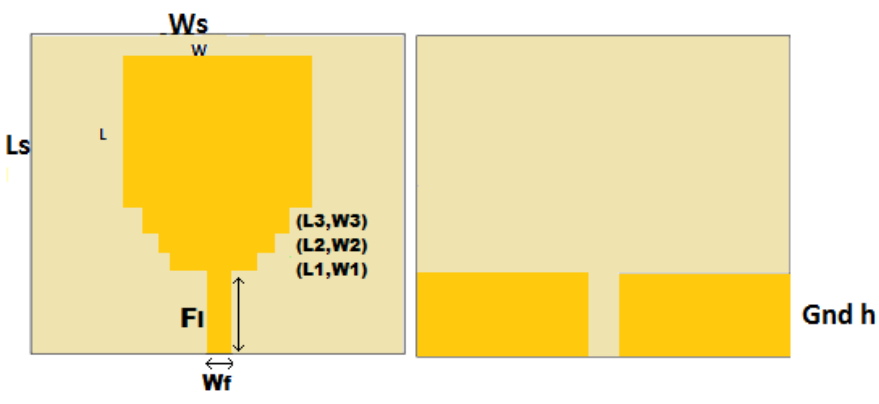

Fig. 1. Design of the proposed antenna.

thus, declining the the antenna's performance. In order to avoid this problem, different techniques are used such as air gap technique in which surface waves are not produced. Further, length of patch plays important role in bandwidth of antenna. Antennas having minimum possible size are considered efficient.

\section{B. Related Work}

Different antennas have been studied in the literature for illustration such as antenna having ring slot of square shape [1], antenna of dual band [2], planar antenna with single, dual, and triple-band notched characteristic [3], CPW-fed with SRR loaded UWB antenna [4], MIMO antenna for UWB applications [5], SRR loaded UWB circular monopole antenna [6], new planar antenna for UWB applications [7],and a printed circular monopole disc antenna [8].

In the literature, several methods are suggested to rise the bandwidth of antenna such as meandered ground plane method [9], patch antenna with integrated band pass filter [10], matching network of optimally designed, and gap-coupled feed [11]. All those methods are proposed to enhance the bandwidth of patch antenna. The proposed methods have advantage as well dis-advantages. Some methods are costly, some methods have very low gain and efficiency.

For the proposed antenna, all the advantages are collected and summarized to design a new antenna for wireless communications.

\section{Contributions}

- The proposed antenna bandwidth is improved, which is suitable for ultra wideband devices. The proposed antenna works in additional band and also achieved multiband characteristics.

- The proposed antenna is easy to fabricate, voltage standing wave ratio is also less than two, and gain is in the acceptable range.

- The proposed antenna has smaller size, lower profile in weight, and linearly polarized.

\section{Structure of the Proposed Patch Antenna}

The basic antenna design is shown in Fig 1. For the proposed antenna, FR4 dielectric material is used for substrate having value of 4.4 and height of $1.6 \mathrm{~mm}$. Our proposed antenna consists of two rectangular shapes patches-one large

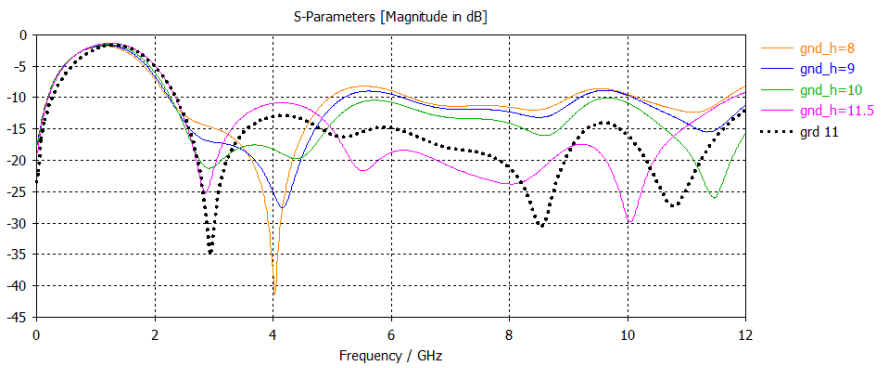

Fig. 2. Simulated return loss in $\mathrm{dB}$ against frequency for different length of ground plane.

TABLE I. Dimensions of the Proposed Antenna

\begin{tabular}{|c|c|c|c|}
\hline Parameter & Value $(\mathrm{mm})$ & Parameter & Value $(\mathrm{mm})$ \\
\hline \hline Sub. height & 1.6 & L1 & 3.2 \\
Ls & 40 (FR4) & L2 & 2.4 \\
Ws & 43 & L3 & 1.2 \\
Gnd h & 11 & W1 & 1.6 \\
Wf & 3 & W2 & 3.6 \\
Fl & 11.9 & W3 & 6 \\
Er & 4.4 & Ls & 43 (other materials) \\
\hline
\end{tabular}

rectangular patch and another small rectangular patch, which also works as a feed line for the antenna. The substrate length and its width are denoted by $L s$ and $W s$, respectively. The feed line is represented by $F l$. Patch antenna is present on front side of the substrate while ground is also on the same side of the substrate. The ground plane is indicated by $\mathrm{Gnd} h$ as presented in Fig.1. CST Microwave Studio is used for antenna simulation in order to obtain more accurate results. All the dimensions of the antenna design are presented in Table I.

\section{Simulation Results of the Proposed Patch ANTENNA}

\section{A. Return Loss, S11}

Simulated return loss of an antenna with different ground planes is shown in Fig.2. The proposed antenna is tested and its results are checked with five different ground planes widths starting from ground width equal to 8 to 11.5 . From Fig.2 it is clear that ground plane having width of eleven gives better results than all other. Antenna with ground plane of eleven gives resonant frequencies at $2.94 \mathrm{GHz}, 5.18 \mathrm{GHz}, 8.54 \mathrm{GHz}$ and $10.78 \mathrm{GHz}$ through return loss of $-35.056 \mathrm{~dB},-16.335$ $\mathrm{dB},-30.589 \mathrm{~dB}$ and $-27.27 \mathrm{~dB}$. Patch of length L, ladder steps at bottom of patch and also ground plane creates those frequencies.

The frequencies for the reason that of the footsteps at the lowermost part of rectangular patch, the rapid changes in the geometry of patch antennas indications to a cutout in the microstrip line [12]. Due to the technique wider bandwidth is obtained, which produces capacitive coupling between the ground plane and patch of the antenna [13]. Magnetic and electric field spreading are altered nearby the discontinuity when the geometry of antenna ups and downs. Thus, the incoherence due to footsteps can be symbolized as corresponding circuit as three times of spilt LC circuit as shown in Fig. 3. Quasi static computation equations from (1) to (7) can be used to express the variables [12].

$$
A=0.00137 \frac{\sqrt{\epsilon_{r e 1}}}{Z o m 1}\left(1-\frac{W 2}{W 1}\right) h \frac{\left(\epsilon_{r e 1}+0.3\right)}{\left(\epsilon_{r e 1}-0.258\right)}
$$




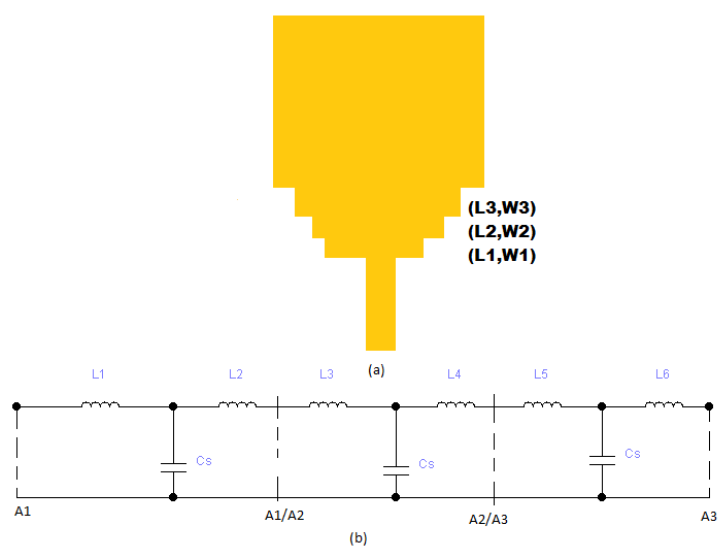

Fig. 3. (a) Micro-strip 3 steps pattern; (b) Corresponding circuit.

$$
\begin{aligned}
& B=\frac{\left.\frac{(W 1}{h}+0.264\right)}{\left(\frac{W 1}{h}+0.8\right)} \\
& C s=A \times B \\
& L 1=\frac{L w 1}{(L w 1+L w 2)} L s \\
& L 2=\frac{L w 2}{(L w 1+L w 2)} L s \\
& L w i=\frac{\left(Z o m \sqrt{\epsilon_{r e}}\right)}{C}(H / m) \\
& L s=0.000987 h\left(1-\frac{Z o m 1}{Z o m 2} \sqrt{\frac{\left(\epsilon_{r e 1}\right.}{\left.\epsilon_{r e 2}\right)}}\right)^{2}(n H)
\end{aligned}
$$

Where, Lwi is on behalf of $i=1,2,3$ point towards inductance per unit length of microstrip of widths W1, W2 and W3. $\epsilon$ and Zom point towards the dielectric constant and microstrip patch line characteristic impedance and also the substrate size $h$ is in $\mathrm{mm}$ [12].

Acting on radiating and matching areas permits monitoring the impedance bandwidth. This slot presents a capacitive reactance, which counteracts with the inductive reactance of the feed. In fact, the technique of cutting the slot at the patch antenna is investigated widely [12]. The proposed antenna shows decent ultra wideband features in terms of return loss and impedance BW, with fractional bandwidth(FBW) of $136.59 \%$ in the simulated result. Furthermore, from return loss graph, we can see the proposed antenna gives better result when ground length is $11 \mathrm{~mm}$.

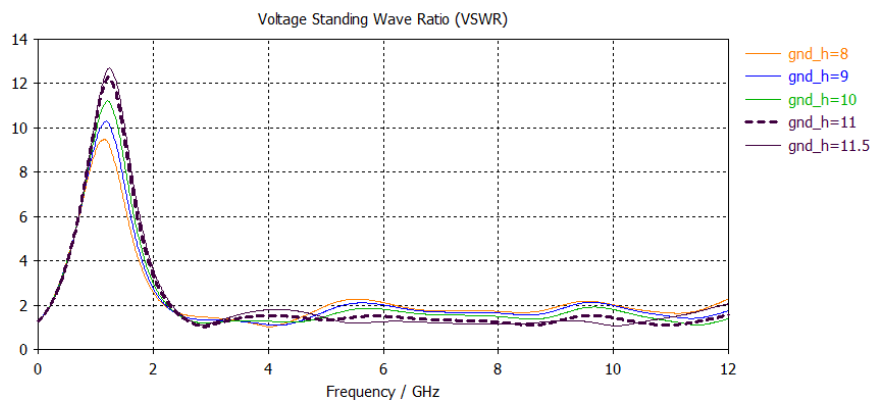

Fig. 4. Simulated VSWR against frequency.

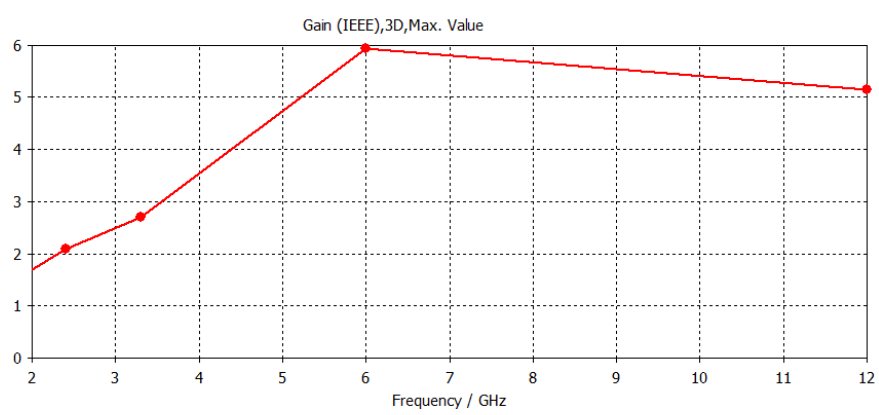

Fig. 5. Simulated result of Gain vs frequency $(\mathrm{GHz})$.

\section{B. Plot of Voltage Standing Wave Ratio (VSWR)}

For different ground widths, the VSWR graph is checked against its frequencies. It is obviously understood that this graphs values are between one and three all the way through simulation frequency. For our attained results, the voltage standing wave ratio for ground width of 11 is good in which value is less than 2 all the way through the simulated frequency results as displayed in the Fig. 4.

\section{Comparison of the Proposed Antenna}

Table II gives a comparison of different antennas w.r.to their sizes, area and bandwidths achieved. The proposed antenna is simulated for different substrate materials and its results are checked and compared with different antennas as shown in Table II. All the antennas attained wideband properties. Now a day's, size of the antenna needs to be minimum due to invention of modern devices and bandwidth should be larger. The proposed antenna is not only smaller in size and area but also has larger bandwidth than all other antennas given in Table II. Gain (dBi) of an antenna is the ratio of power transferred by an antenna in a specified direction and the power transferred in that direction by a perfectly effective isotropic radiator in that direction. Fig. 5 shows the information about the gain along with frequency on horizontal side. It is noticed that the gain of antenna is positive and acceptable. Negative gain shows the losses of an antenna. Gain of the proposed antenna lies between 2 and 6 throughout the simulated frequency.

\section{Radiation Pattern of an Antenna}

E plane is the one at which the theta cuts of at $90^{\circ}$ and $\mathrm{H}$ plane is that one at which phi cuts at $90^{\circ}$. From Fig. 6, it can be seen that radiation patterns show a guiding performance 
TABLE II. COMParison of the Proposed Antenna with Different Antennas

\begin{tabular}{|c|c|c|c|c|c|c|}
\hline Ref. & Antenna type & Freq. (GHz) & $\mathrm{ABW}(\mathrm{GHz})$ & FBW & Material & Area $(\mathrm{L} \times \mathrm{W})$ \\
\hline [1] & Ring slot antenna & $3-11$ & $\mathrm{ABW}=8 \mathrm{GHz}$ & $\mathrm{FBW}=114.2 \%$ & RO4003B $\epsilon_{r}=3.4$ & $12000 \mathrm{~m}^{2}$ \\
\hline \multirow[t]{2}{*}{ [7] } & Planar UWB antenna & $3.1-10.6$ & $\mathrm{ABW}=7.5 \mathrm{GHz}$ & $\mathrm{FBW}=109.4 \%$ & $\mathrm{RO} 4003 \epsilon_{r}=3.38$ & $5850 \mathrm{~m}^{2}$ \\
\hline & Proposed antenna (using material RO4003) & $2.35-13.5$ & $\mathrm{ABW}=11.15 \mathrm{GHz}$ & $\mathrm{FBW}=140.6 \%$ & RO4003 $\epsilon_{r}=3.38$ & $1849 \mathrm{~m}^{2}$ \\
\hline \multirow[t]{2}{*}{ [3] } & Planar antenna & $2.5-12$ & $\mathrm{ABW}=9.5 \mathrm{GHz}$ & $\mathrm{FBW}=131.1 \%$ & RO3003h $\epsilon_{r}=3$ & $2500 \mathrm{~m}^{2}$ \\
\hline & Proposed antenna (using material RO3003) & $2.38-13.82$ & $\mathrm{ABW}=11.44 \mathrm{GHz}$ & $\mathrm{FBW}=141.5 \%$ & $\mathrm{RO} 3003 \epsilon_{r}=3.00$ & $1849 \mathrm{~m}^{2}$ \\
\hline [4] & SRR-loaded UWB antenna & $2.37-10.93$ & $\mathrm{ABW}=8.56 \mathrm{GHz}$ & $\mathrm{FBW}=128.7 \%$ & Taconic $\epsilon_{r}=2.33$ & $2500 \mathrm{~m}^{2}$ \\
\hline \multirow[t]{2}{*}{ [6] } & Circular monopole antenna & $2.6-10.8$ & $\mathrm{ABW}=8.2 \mathrm{GHz}$ & $\mathrm{FBW}=122.3 \%$ & Taconic $\epsilon_{r}=2.33$ & $2500 \mathrm{~m}^{2}$ \\
\hline & Proposed antenna (using material Taconic) & 2.4-14.55 & $\mathrm{ABW}=12.15 \mathrm{GHz}$ & $\mathrm{FBW}=143.3 \%$ & Taconic $\epsilon_{r}=2.33$ & $1849 \mathrm{~m}^{2}$ \\
\hline$[2]$ & Dual band antenna & $2.8-10.6$ & $\mathrm{ABW}=7.8 \mathrm{GHz}$ & $\mathrm{FBW}=116.4 \%$ & FR4 $\epsilon_{r}=4.6$ & $1720 \mathrm{~m}^{2}$ \\
\hline [5] & MIMO antenna for UWB & $3.1-12$ & $\mathrm{ABW}=8.9 \mathrm{GHz}$ & $\mathrm{FBW}=117.8 \%$ & FR4 $\epsilon_{r}=4.4$ & $1820 \mathrm{~m}^{2}$ \\
\hline \multirow[t]{2}{*}{ [8] } & Printed circular disc monopole & $2.69-10.16$ & $\mathrm{ABW}=7.47 \mathrm{GHz}$ & $\mathrm{FBW}=116.2 \%$ & FR4 $\epsilon_{r}=4.7$ & $2100 \mathrm{~m}^{2}$ \\
\hline & Proposed antenna (using material FR4) & $2.33-12.4$ & $\mathrm{ABW}=10.064 \mathrm{GHz}$ & $\mathrm{FBW}=136.5 \%$ & FR4 $\epsilon_{r}=4.4$ & $1720 \mathrm{~m}^{2}$ \\
\hline
\end{tabular}
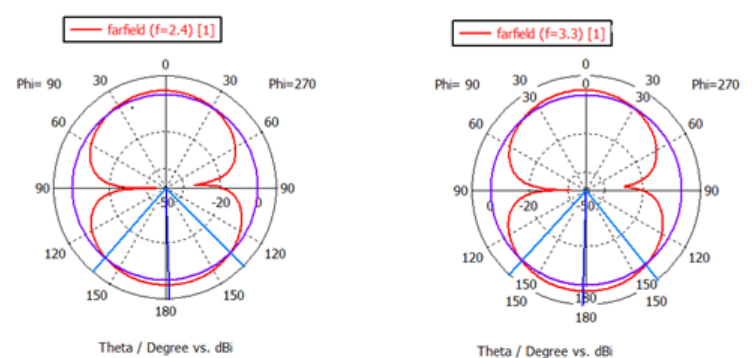

Theta / Degree vs. dBi
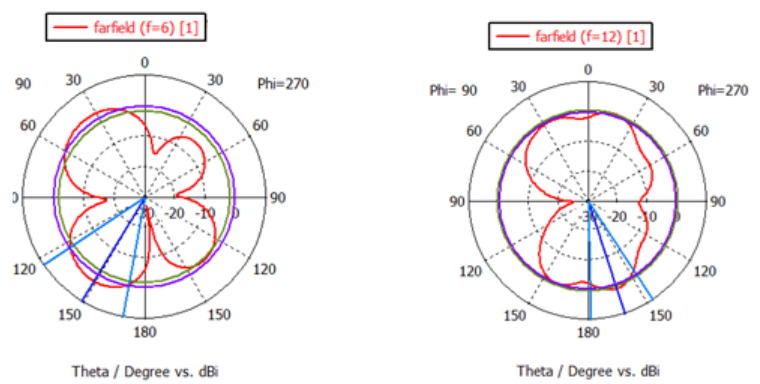

Fig. 6. Radiation patterns at phi cut of 0 degree and at theta cut of 90 degree at (a) $2.4 \mathrm{GHz}$, (b) $3.3 \mathrm{GHz}$, (c) $6 \mathrm{GHz}$, and (d) $12 \mathrm{GHz}$.

such as the core lobe direction is towards at $0^{0}$ and $180^{\circ}$. It means that absorption of the field concentrate on sides of patch of antenna. For time being, from the front and back part of the patch of an antenna lobe suppressed at $90^{\circ}$ and $270^{\circ}$ degree, respectively. Fig. 6(b) shows the same pattern as given in Fig. 6(a), while Fig. 6(c) and Fig. 6(d) display the central lobe direction at the front patch antenna from $0^{0}$ to $180^{\circ}$. More lobes are also observed at higher frequencies. The radiation pattern shows omni directional behavior at low frequencies and linear directional behavior at higher frequencies.

\section{CONCLUSIONS AND FUtURE WORK}

The proposed antenna showed good ultra wideband features, which have simulation results from $2.33 \mathrm{GHz}$ to 12.4 $\mathrm{GHz}$ and fractional bandwidth of $136.59 \%$. The proposed antenna also covers range of WIMAX, blue-tooth, wireless fidelity, and satellite communications for both uplink and downlink channels. The scale of VSWR is also less than 2 throughout the achieved bandwidth. The proposed antenna has small geometrical size and thus, is suitable for telecommunication applications. In future work, we will try to further increase the bandwidth and to add more communication bands for wireless applications such as global system for mobile communication and universal mobile telecommunications system.

\section{REFERENCES}

[1] S. Sadat, M. Fardis, F. Geran, G. Dadashzadeh, N. Hojjat, and M. Roshandel, "A compact microstrip square-ring slot antenna for uwb applications," in 2006 IEEE Antennas and Propagation Society International Symposium, July 2006, pp. 4629-4632.

[2] M. T. Yassen, J. Ali, M. Hussan, H. Alsaedi, and A. Salim, "Extraction of dual-band antenna response from uwb based on current distribution analysis," Technical Report, MRG 6-2016, Microwave Research Group, University of Technology, Iraq, Tech. Rep., 2016.

[3] I. Vendik, A. Rusakov, K. Kanjanasit, J. Hong, and D. Filonov, "Ultrawideband (uwb) planar antenna with single-, dual-, and triple-band notched characteristic based on electric ring resonator," IEEE Antennas and Wireless Propagation Letters, 2017.

[4] H. Peng, C. Wang, L. Zhao, and J. Liu, "Novel srr-loaded cpw-fed uwb antenna with wide band-notched characteristics," International Journal of Microwave and Wireless Technologies, vol. 9, no. 4, pp. 875-880, 2017.

[5] S. Naser and N. Dib, "Analysis and design of mimo antenna for uwb applications based on the super-formula," in Electronic Devices, Systems and Applications (ICEDSA), 2016 5th International Conference on. IEEE, 2016, pp. 1-3.

[6] J. Y. Siddiqui, C. Saha, and Y. M. Antar, "Compact srr loaded uwb circular monopole antenna with frequency notch characteristics," IEEE Transactions on Antennas and Propagation, vol. 62, no. 8, pp. 40154020, 2014.

[7] A. Mehdipour, K. Mohammadpour-Aghdam, and R. Faraji-Dana, "A new planar ultra wideband antenna for uwb applications," in Antennas and Propagation Society International Symposium, 2007 IEEE. IEEE, 2007, pp. 5127-5130.

[8] J. Liang, C. C. Chiau, X. Chen, and C. G. Parini, "Study of a printed circular disc monopole antenna for uwb systems," IEEE transactions on antennas and propagation, vol. 53, no. 11, pp. 3500-3504, 2005.

[9] J.-S. Kuo and K.-L. Wong, "A compact microstrip antenna with meandering slots in the ground plane," Microwave and Optical Technology Letters, vol. 29, no. 2, pp. 95-97, 2001.

[10] M. H. Badjian, C. K. Chakrabarty, G. C. Hock, and S. Devkumar, "An impulse uwb patch antenna with integrated bandpass filter," in Telecommunication Technologies 2008 and 2008 2nd Malaysia Conference on Photonics. NCTT-MCP 2008. 6th National Conference on. IEEE, 2008, pp. 166-169.

[11] P. Hall, "Probe compensation in thick microstrip patches," Electronics Letters, vol. 23, no. 11, pp. 606-607, 1987.

[12] I. J. Bahl, Lumped elements for RF and microwave circuits. Artech house, 2003.

[13] I. Pele, Y. Mahe, A. Chousseaud, S. Toutain, and P. Garel, "Antenna design with control of radiation pattern and frequency bandwidth," in Antennas and Propagation Society International Symposium, 2004. IEEE, vol. 1. IEEE, 2004, pp. 783-786. 